\title{
OPTIMAL GOVERNMENT SUPPORT POLICY TOWARDS TECHNOLOGY DEVELOPMENT CONSIDERING THE CHALLENGES OF CONFLICT OF INTERESTS, ETHICAL AND STRUCTURAL PROBLEMS
}

\author{
Mahdi Bagheri Nasrabadi ${ }^{1}$, Abdullah $\mathrm{JAssbi}^{2, *}$ Ali Bonyadi Naeini ${ }^{1}$ And \\ SAEID SHAVVALPOUR ${ }^{1}$
}

\begin{abstract}
One of the main ways of economic development is technological innovation development. The support provided by the government and the policies adopted for technology developments are important issues in the context of technology and innovation policymaking. On the other hand, the structural issues in some countries, especially in Iran, as well as the conflict of interests and ethical problems, are of crucial importance in large-scale technology development projects. The present paper addresses governmental policies and support and the underpinning parameters given the points mentioned about the economic and technological development of Iran. In this study, we first interviewed some experts, and the results were employed as inputs of the quantitative model. The important parameters influencing the determination of governmental support and policy type were also addressed. The long-term behavior of the public and private sectors as two key players were analyzed by the evolutionary game theory and their strategies were solved by replicative dynamic equations. Finally, a numerical study was conducted for a real case in Iran to better understand the features of the game model in real conditions. The results of the case study show that the main approach of the government should be legal monitoring although the minimum incentive policies and supports should also be in place. The sensitivity analysis of some major parameters reveals that the main factor in project implementation is to consider the income and costs of the private sector. The governmental policy should be based on preparing incentive mechanisms at an appropriate level and then precise legal monitoring, which will lead to technology development with the cooperation of the parties, minimum ethical problems, and the minimization of the impact of structural problems, including sanctions.
\end{abstract}

Received July 26, 2020. Accepted February 12, 2021.

\section{INTRODUCTION}

Governments as one of the biggest economic players have an essential role to play in technological economic development. In the past, extensive research has focused on proper governmental policies towards the

Keywords. Technology development, government support policy, cooperation, conflict of interests, moral hazards.

1 Management, Economic and Progress engineering department at IUST, 0098 Tehran, Iran.

2 Industrial engineering department at IUST, 0098 Tehran, Iran.

*Corresponding author: iau.history@yahoo.com 
private-sector contractors as to which policy can help accomplish the goals, such as the full development of technology and optimal welfare of the private sector in both main players of technology development projects, i.e., the government and the private sector. On the other hand, the literature and interviews with experts show that in technology development projects, a sound governmental policy towards the private sector can contribute to accomplishing the project goals including the enhancement of the welfare of the private-sector enterprises, as well as national large-scale goals including technology development, the creation of sustainable employment, economic growth, and other macroeconomic and microeconomic parameters, along with the environmental considerations. Previous studies have shown how governmental policies influence tangible values in different societies $[16,28,32,39,41,43]$ and then they have continuously focused on technology-oriented governmental policies and entrepreneurial activities $[17,19,20]$. Some other studies have dealt with the role of government subsidies and some have looked at the role of governmental regulation and monitoring on innovation development in different countries [26]. There is no consensus among scientists as to the impact of governmental support on the performance of enterprises and their growth rate. Especially when it comes to innovation and technology development, firms are unable to compete in the free market based on the supply and demand rule. The government can help firms with production scale, the compensation of environmental costs, and so on [21]. It has been reported that government subsidies can influence the performance of the firms significantly [54]. On the other hand, some researchers argue that these subsidies have negative impacts on the firms and industry due to the loss of the firms, the politicians' interest in gaining political profit instead of economic profit, and unjust and inefficient allocation of subsidy $[2,6,9,13,23,25,46]$. However, the simultaneous impacts of both methods have not been studied yet. Also, no research has answered the question as to which policy is more influential on innovation and technology development.

Although different studies have investigated the type of governmental intervention, none has ever considered the macroeconomic parameters in developing countries along with two important issues of ethical problems and conflict of interests. Also, sensitivity analysis on the key parameters and different policies and the determination of proper policies, which have been studied to a lesser extent, were explored in the present research in detail. Similarly, the evolutionary game theory, which was used in the present research, has rarely been adopted in studies on policymaking despite its high effectiveness. Another point to consider is that few studies have explored the effect of supportive policies of governments on innovation and technology of a certain industry or sector in large-scale technology development projects in developing countries.

The research question is, "What is the appropriate support policy for the government towards the private sector in technology development projects - incentive policy or legal monitoring"?

To answer this question, the followings are addressed:

- Investigating the attributes of developing countries, such as exchange rate instability, inflation, economic recession, and sanctions when it specifically comes to Iran.

- Investigating ethical problems and the conflict of interests between the government and the private sector.

- Investigating the main parameters affecting projects using sensitivity analysis and identifying the extent to which they influence the adoption of a proper policy.

The case study is the project of ten commodities groups of the oil industry. This is one of the biggest technology development projects in Iran and the authors of the present research were involved as the main team of field study in that project for three years during which they investigated over 79 firms.

The paper is organized as follows. The first section reviews the relevant literature. The methodology section first presents the main assumptions of the game model and then, extracts the strategy formula, repetitive equations dynamics, and stability analysis. Then, a case study is addressed in which the computational results and vision on this policy are analyzed and reported. The paper is finally ended with some concluding points and the consequences of the policy. 


\section{Litrature REVIEW}

\subsection{Project for construction of ten oil industry commodity groups}

The localization of goods and equipment required by the oil industry has always been a concern of managers and experts in this industry. In the 1990s, the process of organizing, regulating, and legislating in the field of domestic manufacturing took place, and in the 2000s, the supportive policies of the Ministry of Petroleum led to an acceptable leap forward in the oil industry. During this period, nearly one hundred thousand pieces of the needs of this huge industry were built in different ways, including reverse engineering, copying, assembly, etc. Manufacturers began to expand research and development and conduct research activities, and innovation was seen in manufacturers.

At the beginning of the 2010s, the oil industry went through the process of reverse engineering and applied the focus on research and technology and the use of new methods of technology development. Then, the Ministry of Petroleum of Iran regulated its activities in various branches to achieve an industry based on knowledge and technology with an endogenous, extroverted, progressive, and dynamic approach. After extensive expert examinations, 10 groups of goods required by the oil industry selected and communicated as follows:

- Project for making source equipment and in-well supplementary field equipment.

- Project to build pumps inside and at the wellhead.

- Project for making all kinds of drilling drills rock, diamond, brainstorming.

- Project for making all kinds of control valves, safety, and accessories.

- Project for making all kinds of pipes.

- Project for making explosion-proof and variable speed electric motors.

- Project for making rotary machines turbine, compressor, pumps including centrifugal.

- Project for making all kinds of alloy steels, including CRYOGENIC steels, refrigeration.

- Project for making measuring instruments in drilling.

- Smart Pigs Project.

Some of the achievements of the project to build ten oil commodity groups.

The formation of the component manufacturing industry and the construction of strategic goods and equipment can lead to important achievements in the period of 0-2 years, which can be mentioned as follows [44]:

- High capacity to affect economic development, industrial development, technology development, and job creation:

In just 10 items of goods and strategic equipment of various industries, up to 2 billion dollars directly and 6 billion dollars indirectly, the annual market volume of this equipment is in the country. The above market volume, if converted into industrial activity, will account for 4-12 percent of the country's GDP. Implementation of this plan could lead to a significant increase in employment, for example, if the ratio of capital to employment in the industrial part of the parts manufacturing sector in Iran is considered to be about $\$ 25000$, and if only half of the imports of the industrial parts manufacturing sector. Oil, gas, petrochemicals, and automobiles ( $\$ 20$ billion a year) will be handed over to domestic companies, creating more than 270000 new jobs in the equipment manufacturing industry.

- Implementing technology policy against the market:

Most of the country's technology development policies at the national and sectoral levels have focused on the supply side of technology, and the lack of effective policies to stimulate demand has been a major shortcoming in recent years. Putting on the market, developing, and equipping the technology of strategic equipment.

- Overflow of the results of the project from the oil industry to other industries:

As mentioned, the manufacturing of various goods and equipment in the industry will have great potential to pour technology into other important industries such as the automotive industry, transportation, energy, and home appliances. Therefore, just as the oil industry is the locomotive of the country's economy, with the successful implementation of this plan, it will have the capacity to become the driving force of Iran's industry and technology. 


\subsection{Government support policy}

Various studies have been conducted on incentive policies or government regulatory and legal policies in the field of technology in various industries and sectors. Krass et al. [24], Drake et al. [14], Wang et al. [48] and Ma et al. [31] have examined the role of tax incentive policies in various technological and environmental areas. Another incentive policy reviewed in the papers is "feed-in-tariff".

Lobel and Perakis [27], Shrimali and Baker [42], Alizamir et al. [1], Ritzenhofen et al. [38], Chemama et al. [10], Cohen et al. [12], and Berenguer et al. [8] studied about consumer subsidy policy and purchase and sales subsidies.

Raz and Ovchinnikov [36] focus on the coordination issue to maximize welfare.

In a context of contracts, Zhou and Huang [57] investigate the effectiveness of fixed amount and discount contracts offered by the government under budget constraint for energy-saving products.

Atasu et al. [57] characterize the optimal decisions for take-back legislation and subsidy under competition.

\subsection{Actors and institutions cooperation}

Experts on collaborative theories believe that different economic, political, and social issues have different strategic structures and that these different structures determine the perspective of cooperation. One of the requirements for achieving this important goal is the cooperation of the main institutions and policymakers including universities, suppliers and customers, service intermediaries, government agencies, and competitors. Belderbos et al. [7], Wind and Mahajan [49], Nieto and Santamaría [33], Tether [45], Wu and Chen [51], Ingram and Roberts [22], Luo et al. [29], Pangarkar and Wu [34], Zhang and Li [53], George et al. [18] and Wu [50] to realize the knowledge-based economy in the country's leading industries, including the oil industry. In the new literature, the models presented for policy-making processes have placed great emphasis on democratic policy-making processes, and on this basis, the cooperation of institutions in policy-making and policy-making is essential. Institutional cooperation is an integral part of the implementation of innovative economic development policies in various industries, including the oil industry.

Therefore, it is necessary to find solutions for win-win cooperation between the involved institutions to optimize the interests of the parties involved and the interests of the system. Such a conflict is abundant in most of the institutional cooperation in national projects in the oil industry, including in the project of ten commodity groups.

\subsection{Moral hazards}

Arrow first introduced the concept of moral hazard in the study of insurance contracts. In that study, he said that insured people may even do destructive or reckless actions to avoid risk. Or, in fire insurance, high-value fire insurance may lead to an intentional fire [3,55]. The concept of ethical problems has also been developed by researchers outside the insurance industry. The title refers to individuals who, in addition to seeking to maximize their profits, also act against other individuals or companies [56].

One of the reasons for the moral dilemma is that project members are dissatisfied with the number of benefits they receive from the contract, and in many cases, this is due to insecurity and incomplete contracts [30,52].

Few studies have examined ethical issues using game theory $[35,40]$. Researchers can analyze the issue of moral hazards using game theory and then provide an incentive or inhibitory mechanism to control moral dilemmas [11]. The new institutional economics, based on the three principles of maximum utilization, limited rationality, and opportunism, has conducted studies to discover ethical behavior [5,52]. Failure to secure the interests of private companies, and consequently the reduction of corporate welfare, increases their moral dilemmas. Ethical problems include not using quality raw materials, not following the required standards, and so on. Cases that may cause irreparable damage to industry and upstream equipment. For example, non-compliance with safety issues in production can lead to fire and destruction of all facilities. Companies are required to fully comply with all safety and quality regulations in production, which will increase their costs and reduce their profitability and well-being, and will inevitably force them to resist the full transfer of technology made by ten commodity 
groups. Another example of a moral dilemma would be the poor quality of parts such as drilling pipes and pumps, the former of which may lead to the closure of wells and the high costs of the latter may lead to the burning of wells and irreparable costs to become an industry.

\section{RESEARCH METHOD}

To develop the research topic model, the theory of evolutionary games theory has been used. To identify and determine the parameters and variables of the model input, expert interviews were used. In this regard, the information of more than 80 companies participating in the tender and more than 20 companies that won the tender were examined. With more than 60 experts in the field of the oil industry, university professors and researchers, and managers of private companies involved in the interview tender, the results were used as input in the model of evolutionary game theory.

To achieve comprehensive equilibrium, a long-term analysis of the actors' policies in the ten commodity project needs to be undertaken, as it is likely that the equilibrium of game theory, in reality, is unstable. In this paper, the evolutionary Game Theory (EGT) is used to analyze actors' behavior because EGT seeks to have an optimal long-term strategy, which is called an evolutionarily stable strategy (ESS) [15]. The initial applications of EGT are in biology. However, EGT also provides insights in economics [37] EGT has been one of the most widely used methods in recent years to analyze the different behaviors of actors in different industries $[15,47,53,58]$.

\subsection{Assumption and notations}

\subsubsection{Assumptions}

The game model assumptions are as follows:

(1) The game model is assumed among two players: Governments, and the Private sector.

(2) The policies envisaged by the government in this project include the application of legal regulations and incentive mechanisms. Although in reality, it is not possible to fully regulate without incentive mechanisms, it is the intention of the researcher and the project team of ten commodity groups to state the main inclination of government in each policy.

(3) Private sectors have two strategies for performing technology development and not performing the development process completely.

(4) Private sectors that are failed to perform technology development are divided into two groups. The first group receives the prepayment but the technology development is performed incompletely and the final products are of low quality. The second group is not capable of performing technology development and thus pays the penalty to the governments.

(5) The notations presented are based on two sources of government objectives and parameters of the private sector. The parameters of the private sector were extracted through interviews with the private sector using the method of interviewing experts.

\subsubsection{Notations}

The following notations are considered in the proposed game model:

$\mathrm{IG}_{g}$ Government income from Direct economic growth.

$\mathrm{IG}_{i g}$ Government income from Indirect economic growth.

$\mathrm{IG}_{j}$ Government income from Job creation.

$\mathrm{CG}_{m}$ The cost imposed on governments for monitoring on contract execution.

$\mathrm{CG}_{p}$ Cost of prepayment paid by governments.

$\mathrm{CG}_{d}$ Cost of damage caused by private sectors to government.

$\mathrm{IG}_{p}$ Penalty received by the government from private sectors.

$\mathrm{IP}_{\mathrm{TD}}$ Private sector income from performing complete technology development. 
$\mathrm{IP}_{v}$ Income from increasing companies' value.

$\mathrm{CP}_{\mathrm{HR}}$ Cost of training human resources.

$\mathrm{CP}_{\mathrm{R} \& \mathrm{D}} \mathrm{R} \& \mathrm{D}$ expenditures.

$\mathrm{CP}_{p}$ Cost of production line for technology development.

$\mathrm{CP}_{B}$ Cost of bank guarantee by private sectors.

$\mathrm{CP}_{f}$ Cost of currency fluctuations.

$\mathrm{CP}_{m}$ Cost of moral hazard.

$x$ The proportion of private sectors breaking the ethics.

$\Pi_{G}$ The profit of governments playing strategies.

$\Pi_{\mathrm{PS}_{j}}$ The profit of private sectors playing strategy $j=T, \mathrm{NT}$.

$X_{G}$ The proportion of government that imposes regulation $\left(0 \leq X_{G} \leq 1\right)$.

$1-X_{G}$ The proportion of governments that utilize incentive.

$X_{P}$ The proportion of private sectors that perform technology development completely $\left(0 \leq X_{P} \leq 1\right)$.

$1-X_{P}$ The proportion of private sectors that do not perform technology development.

\subsection{Evolutionary game analysis}

In this section, the long-term behavior of two sectors of government and the private sector, each of which has two strategies, is examined using evolutionary game theory.

The players' overall strategy framework is as follows:

- Formulate each player's strategy mix.

- Interpret each player's behavior using a long-term replicator dynamic.

- Obtain an evolutionarily stable strategy by solving replicator dynamic equations (Tab. 1).

TABLE 1. The second player evolutionary game among governments and private sectors.

\begin{tabular}{llll}
\hline \hline & Private sectors & \\
\hline & $\begin{array}{l}T: \text { Performing Technology } \\
\text { development }\left(X_{P}\right)\end{array}$ & $\begin{array}{l}\text { NT: Not performing Tech- } \\
\text { nology development } \\
\left(1-X_{P}\right)\end{array}$ \\
\hline \multirow{2}{*}{ Governments } & $R:$ Regulation $\left(X_{G}\right)$ & $1:\left(\Pi_{G_{R-T}}, \Pi_{P_{R-T}}\right)$ & $2:\left(\Pi_{G_{R-\mathrm{NT}}}, \Pi_{P_{R-\mathrm{NT}}}\right)$ \\
& $I:$ Incentive $\left(1-X_{G}\right)$ & $3:\left(\Pi_{G_{I-T}}, \Pi_{P_{I-T}}\right)$ & $4:\left(\Pi_{G_{I-\mathrm{NT}}}, \Pi_{P_{I-\mathrm{NT}}}\right)$ \\
\hline
\end{tabular}

\subsubsection{Strategy formulation}

The payoff formulations of strategies 1-8 are presented, as follows:

- Strategy $R-T$.

The governments' profit $=$ direct economic growth + indirect economic growth + income of job creation monitoring cost - prepayment cost.

The private sectors' profit $=$ income of complete technology development + income of increasing companies' reputation + prepayment received from the government - HR training cost $-\mathrm{R} \& \mathrm{D}$ cost - production cost bank guarantee cost - the cost of currency fluctuations

$$
\begin{aligned}
\Pi_{G_{R-T}} & =\mathrm{IG}_{g}+\mathrm{IG}_{i g}+\mathrm{IG}_{j}-\mathrm{CG}_{m}-\mathrm{CG}_{p} \\
\Pi_{P_{R-T}} & =\mathrm{IP}_{\mathrm{TD}}+\mathrm{IP}_{v}+\mathrm{CG}_{p}-\mathrm{CP}_{H R}-\mathrm{CP}_{\mathrm{R} \& \mathrm{D}}-\mathrm{CP}_{P}-\mathrm{CP}_{B}-\mathrm{CP}_{F} .
\end{aligned}
$$

- Strategy $R-$ NT. 
The governments' profit $=(1-x)($ Penalty received from private sectors $)-x($ Damage cost $)-$ Monitoring cost - Prepayment cost.

The private sectors' profit $=x$ (income of complete technology development + income of increasing companies' reputation + prepayment received from the government - the cost of moral hazard) $-(1-x)$ (prepayment received from the government - penalty received by governments)

$$
\begin{aligned}
\Pi_{G_{R-\mathrm{NT}}} & =(1-x) \mathrm{IG}_{P}-x \mathrm{CG}_{d}-\mathrm{CG}_{m}-\mathrm{CG}_{p} \\
\Pi_{P_{R-\mathrm{NT}}} & =x\left(\mathrm{IP}_{\mathrm{TD}}+\mathrm{IP}_{v}+\mathrm{CG}_{p}-\mathrm{CP}_{m}\right)+(1-x)\left(\mathrm{CG}_{p}-\mathrm{IG}_{p}\right) .
\end{aligned}
$$

- Strategy $I-T$.

The governments' profit $=$ Direct economic growth + Indirect economic growth + Income of job creation subsidies are given to the private sectors - prepayment cost.

The private sectors' profit $=$ Income of complete technology development + income of increasing companies' reputation + subsidies received from government + prepayment received from the government - HR training cost - R\&D cost - Production cost - bank guarantee cost - the cost of currency fluctuations

$$
\begin{aligned}
\Pi_{G_{I-T}} & =\mathrm{IG}_{g}+\mathrm{IG}_{i g}+\mathrm{IG}_{j}-\mathrm{CG}_{s}-\mathrm{CG}_{p} \\
\Pi_{P_{I-T}} & =\mathrm{IP}_{\mathrm{TD}}+\mathrm{IP}_{v}+\mathrm{CG}_{S}+\mathrm{CG}_{p}-\mathrm{CP}_{H R}-\mathrm{CP}_{\mathrm{R} \& \mathrm{D}}-\mathrm{CP}_{P}-\mathrm{CP}_{b}-\mathrm{CP}_{f} .
\end{aligned}
$$

- Strategy $I-$ NT.

The governments' profit $=(1-x)$ (penalty received from private sectors $)-x$ (damage cost $)-$ subsides given to the private sectors - prepayment cost.

The private sectors' profit $=x$ (income of complete technology development + income of increasing companies' reputation + prepayment received from government + subsidies received from the government - the cost of moral hazard $)+(1-x)$ (prepayment received from government + subsidies received from the government - penalty received by governments)

$$
\begin{aligned}
& \Pi_{G_{I-\mathrm{NT}}}=(1-x) \mathrm{IG}_{P}-x \mathrm{CG}_{d}-\mathrm{CG}_{s}-\mathrm{CG}_{p} \\
& \Pi_{P_{R-\mathrm{NT}}}=x\left(\mathrm{IP}_{\mathrm{TD}}+\mathrm{IP}_{v}+\mathrm{CG}_{p}+\mathrm{CG}_{s}-\mathrm{CP}_{m}\right)+(1-x)\left(\mathrm{CG}_{p}+\mathrm{CG}_{s}-\mathrm{IG}_{p}\right) .
\end{aligned}
$$

\subsubsection{Stability analysis}

Suppose that $\mathrm{EG}_{R}(t)$ and $\mathrm{EG}_{I}(t)$ denote the expected payoff for the governments applying regulations and imposing subsidies at time $t$, respectively. Moreover, $\overline{\mathrm{EG}}(t)$ it is the average payoff of the governments in the population at time $t$. Similarly, $\mathrm{EP}_{I}(t), \mathrm{EP}_{R}(t)$ and $\overline{\mathrm{EP}}(t)$ are the notations used for the private sectors selecting their strategies. The calculations are presented as follows:

$$
\begin{aligned}
\mathrm{EG}_{R}(t) & =X_{P} \Pi_{G_{R-T}}+\left(1-X_{P}\right) \Pi_{G_{R-\mathrm{NT}}} \\
\mathrm{EG}_{I}(t) & =X_{P} \Pi_{G_{I-T}}+\left(1-X_{P}\right) \Pi_{G_{I-\mathrm{NT}}} \\
\overline{\mathrm{EG}}(t) & =X_{G} \mathrm{EG}_{R}(t)+\left(1-X_{G}\right) \mathrm{EG}_{I}(t) \\
& =X_{G} X_{P} \Pi_{G_{R-T}}+X_{G}\left(1-X_{P}\right) \Pi_{G_{R-\mathrm{NT}}}+\left(1-X_{G}\right) X_{P} \Pi_{G_{I-T}}+\left(1-X_{G}\right)\left(1-X_{P}\right) \Pi_{G_{I-\mathrm{NT}}} \\
\mathrm{EP}_{\mathrm{TD}}(t) & =X_{G} \Pi_{P_{R-T}}+\left(1-X_{G}\right) \Pi_{P_{I-T}} \\
\operatorname{EP}_{\mathrm{NTD}}(t) & =X_{G} \Pi_{P_{R-\mathrm{NT}}}+\left(1-X_{G}\right) \Pi_{P_{I-\mathrm{NT}}} \\
\overline{\mathrm{EP}}(t) & =X_{p} \mathrm{EP}_{\mathrm{TD}}(t)+\left(1-X_{p}\right) \mathrm{EP}_{\mathrm{NTD}}(t) \\
& =X_{P} X_{G} \Pi_{P_{R-T}}+X_{P}\left(1-X_{G}\right) \Pi_{P_{I-T}}+\left(1-X_{P}\right) X_{G} \Pi_{P_{R-\mathrm{NT}}}+\left(1-X_{P}\right)\left(1-X_{G}\right) \Pi_{P_{I-\mathrm{NT}}}
\end{aligned}
$$

To find the evolutionarily stable strategy, the following replicator dynamic equations are applied which determine the evolution of strategies played by players. The ESS is derived by equating the replicator dynamic equations 
TABLE 2 .

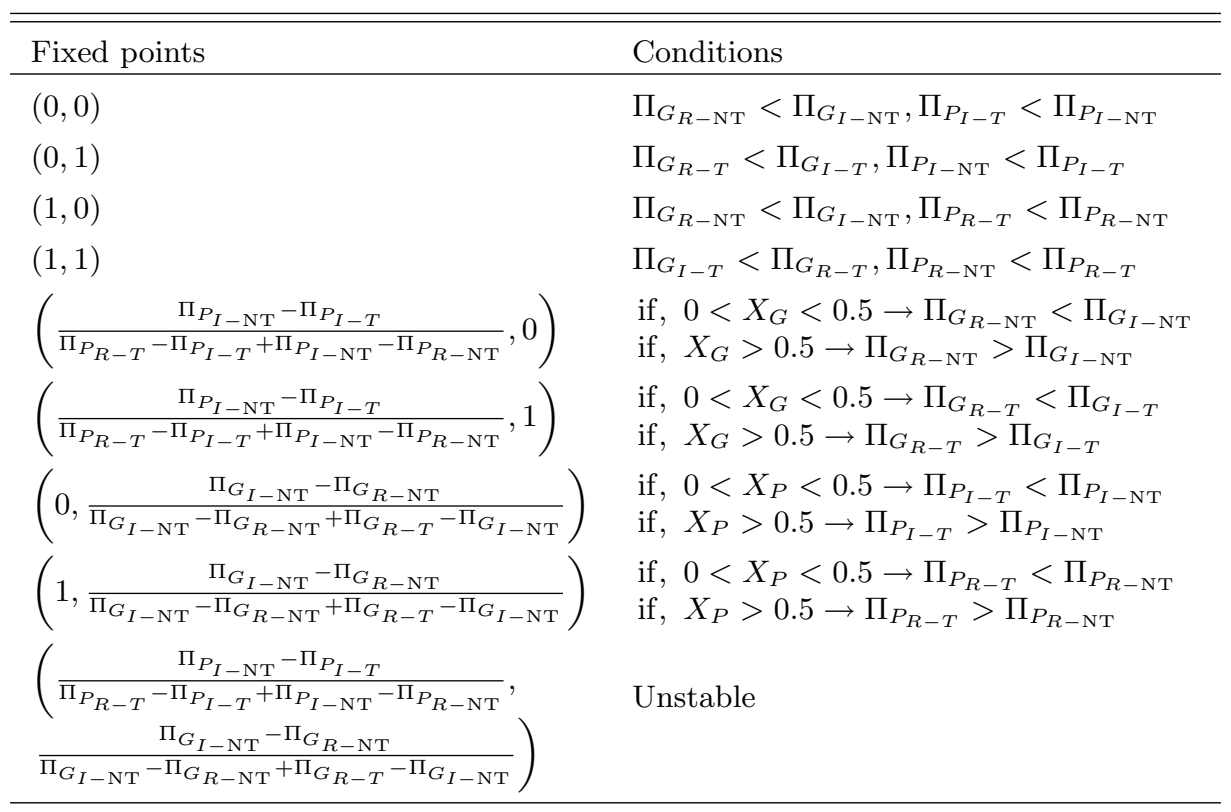

to zero and checking the stability of the derived points using the Jacobian matrix.

$$
\begin{aligned}
A\left(X_{G}, X_{P}\right) & =\frac{\mathrm{d} X_{G}(t)}{\mathrm{d} t}=X_{G}\left[\mathrm{EG}_{R}-\overline{\mathrm{EG}}(t)\right] \\
& =X_{G}\left(1-X_{G}\right)\left[X_{p} \Pi_{G_{R-T}}+\left(1-X_{p}\right) \Pi_{G_{R-\mathrm{NT}}}-X_{p} \Pi_{G_{I-T}}-\left(1-X_{p}\right) \Pi_{G_{I-\mathrm{NT}}}\right] \\
B\left(X_{G}, X_{P}\right) & =\frac{\mathrm{d} X_{P}(t)}{\mathrm{d} t}=X_{P}\left[\mathrm{EP}_{\mathrm{TD}}-\overline{\mathrm{EP}}(t)\right] \\
& =X_{P}\left(1-X_{P}\right)\left[X_{G} \Pi_{P_{R-T}}+\left(1-X_{G}\right) \Pi_{P_{I-T}}-X_{G} \Pi_{P_{R-\mathrm{NT}}}-\left(1-X_{G}\right) \Pi_{P_{I-\mathrm{NT}}}\right] \\
J & =\left[\begin{array}{ll}
\frac{\partial A\left(X_{G}, X_{P}\right)}{\partial X_{G}} & \frac{\partial A\left(X_{G}, X_{P}\right)}{\partial X_{P}} \\
\frac{\partial B\left(X_{G}, X_{P}\right)}{\partial X_{G}} & \frac{\partial B\left(X_{G}, X_{P}\right)}{\partial X_{P}}
\end{array}\right] .
\end{aligned}
$$

All the derived fixed points and the stability conditions are listed in Table 2 as follows.

\subsection{Computational results}

This section calculates the profits of each player in the case study of each strategy, solving the dynamic replication equations and testing the stability of all derived fixed points.

All the data in the proposed case study are summarized in Table 3 below.

In the proposed case in Iran, the profit of each player is calculated and the stability of the fixed points is checked. The results are listed in Table 4. As it is seen, $\Pi_{G_{I-T}}<\Pi_{G_{R-T}}, \Pi_{P_{R-\mathrm{NT}}}<\Pi_{P_{R-T}}$ it is satisfied therefore, the ESS is $(1,1)$ showing that the stable strategy for governments is regulation. Moreover, performing technology development is a stable strategy for private sectors. To have a more precise look into the long-term behavior of governments and private sectors, the trajectories of the replicator dynamics are plotted. Converging trajectories to point $(1,1)$ can be seen in Figure 1. 
TABLE 3 .

\begin{tabular}{llll}
\hline \hline $\mathrm{IG}_{g}$ & $4000(\mathrm{MIRR})$ & $\mathrm{IP}_{\mathrm{TD}}$ & $2400(\mathrm{MIRR})$ \\
$\mathrm{IG}_{i g}$ & $1200(\mathrm{MIRR})$ & $\mathrm{IP}_{v}$ & $4800(\mathrm{MIRR})$ \\
$\mathrm{IG}_{j}$ & $4000(\mathrm{MIRR})$ & $\mathrm{CP}_{\mathrm{HR}}$ & $80(\mathrm{MIRR})$ \\
$\mathrm{CG}_{m}$ & $7.5(\mathrm{MIRR})$ & $\mathrm{CP}_{\mathrm{R} \& \mathrm{D}}$ & $400(\mathrm{MIRR})$ \\
$\mathrm{CG}_{p}$ & $1600(\mathrm{MIRR})$ & $\mathrm{CP}_{p}$ & $1200(\mathrm{MIRR})$ \\
$\mathrm{CG}_{d}$ & $40000(\mathrm{MIRR})$ & $\mathrm{CP}_{B}$ & $590(\mathrm{MIRR})$ \\
$\mathrm{CG}_{s}$ & $576(\mathrm{MIRR})$ & $\mathrm{CP}_{m}$ & $2000(\mathrm{MIRR})$ \\
$\mathrm{IG}_{p}$ & $3280(\mathrm{MIRR})$ & $x$ & 0.5 \\
\hline
\end{tabular}

TABLE 4. The pairs of fixed points and the stability conditions.

\begin{tabular}{llll}
\hline \hline$\Pi_{G_{R-T}}$ & 7592.5 & $\Pi_{P_{R-T}}$ & 3330 \\
$\Pi_{G_{R-\mathrm{NT}}}$ & -19967.5 & $\Pi_{P_{R-\mathrm{NT}}}$ & 2560.0 \\
$\Pi_{G_{I-T}}$ & 7024 & $\Pi_{P_{I-T}}$ & 3906 \\
$\prod_{G_{I-\mathrm{NT}}}$ & -20536.0 & $\Pi_{P_{I-\mathrm{NT}}}$ & 3136.0 \\
\hline
\end{tabular}

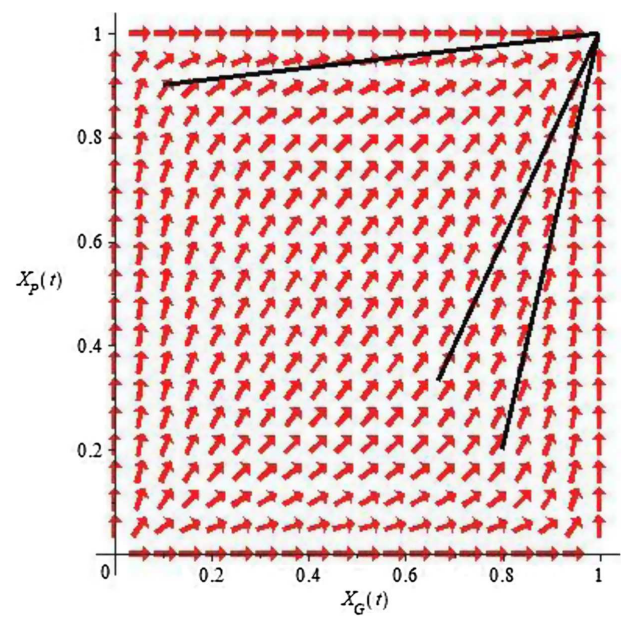

Figure 1. The trajectories convergence to the ESS in the long-term.

\section{Discussions \& POLICY INSIGHT}

\subsection{The effect of Government income for direct economic growth on long-term behavior}

To illustrate the effect of Government income for Direct economic growth on policy selection, based on Government income for Direct economic growth, the sensitivity analysis is performed, which are shown in Figure 2. As it is seen, Government income for Direct economic growth doesn't have a considerable effect on game results. Indeed, the increase or decrease in government income does not affect the behavior and decision of the government and the private sector. 

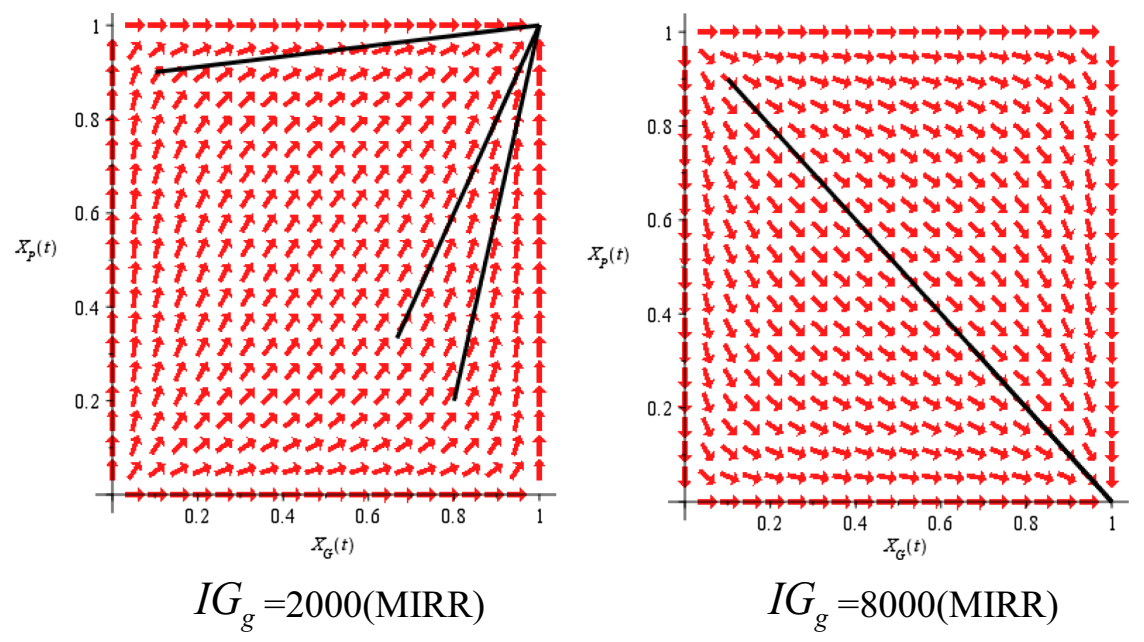

Figure 2. The effect of governments' income $\left(\mathrm{IG}_{g}\right)$ on the long-term strategies.

\subsection{The effect of Private sector income from performing complete technology development on long-term behavior}

To illustrate the effect of Private sector income from performing complete technology development on longterm behavior, the effects of Private sector income from performing complete technology development on policy selection, Sensitivity analysis based on private-sector income has been investigated. It has been found that private sector income has a significant influence on game results as shown in Figure 3. With a $50 \%$ decline in private sector revenue, private sectors tend not to perform technology development and the government's strategy is still the regulation. The convergence of the trajectories from $(1,1)$ to $(0,1)$ clearly shows this, by a 2 -fold increase in private sector revenue, the long-term behavior of government tent to incentive strategy. Therefore, government incentive policies such as income have a significant effect on changing the behavior of the private sector to perform contract and technology development.

\subsection{The effect of Cost of prepayment paid by governments on long-term behavior}

To illustrate the effect of Cost of prepayment paid by governments on policy selection, Based on the cost of prepayment paid by governments sensitivity analysis is performed, which are shown in Figure 4 . As it is seen, the Cost of prepayment paid by governments doesn't have a considerable effect on game results. With a $50 \%$ decline in the cost of the private sector or Increase by 100\%, private sectors still tend to perform technology development, and the government's strategy tent to the regulatory policies. Indeed, the increase or decrease in prepayments does not affect the behavior and decision of the government and private sector.

\subsection{The effect of Cost of CHR, R\&D, and production on the long-term behavior}

To illustrate the effect of Cost of CHR, R\&D, and production on policy selection, based on of Cost of CHR, $\mathrm{R} \& \mathrm{D}$, and production, sensitivity analysis is performed, which are shown in Figure 5. As is seen, the Cost of CHR, R\&D, and production has a considerable effect on game results. With a $50 \%$ decline in the cost of the private sector, private sectors still tend to perform technology development but the government's strategy tent to the incentive policies. By a 2-fold increase in the cost, the long-term behavior of the private sector shifts to not performing technology development. The convergence of the trajectories from $(1,1)$ to $(0,1)$ clearly shows this. Therefore, increasing costs can prevent performing contract and technology development. 

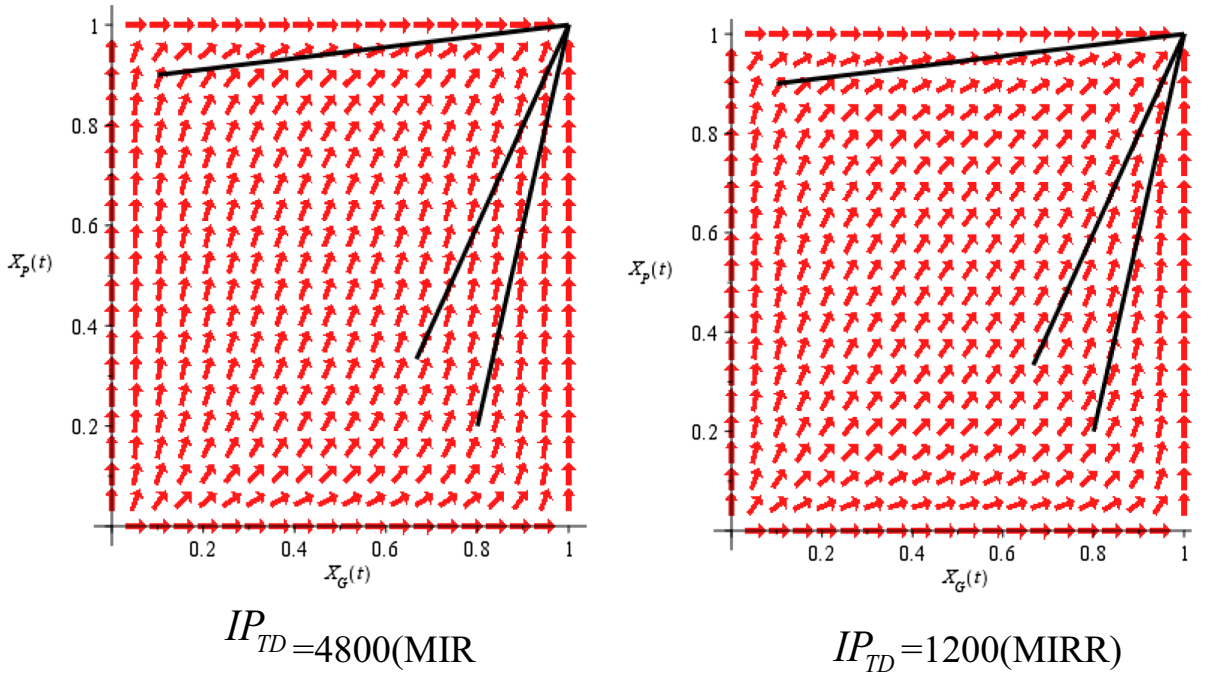

Figure 3. The effect of Private sector income from performing complete technology development $\left(\mathrm{IP}_{\mathrm{TD}}\right)$ on the long-term strategies.
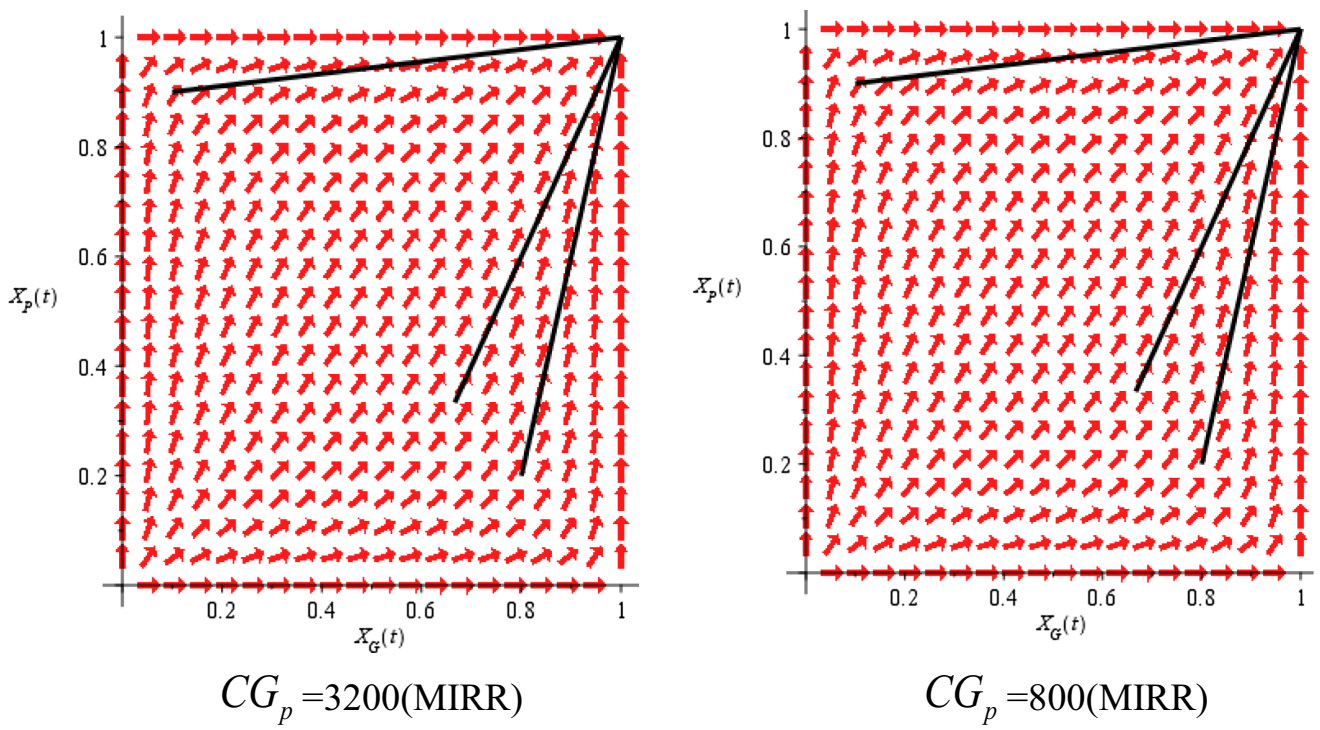

FiguRE 4 . The effect of the Cost of prepayment paid by governments $\left(\mathrm{CG}_{p}\right)$ on the long-term strategies.

\subsection{The effect of Cost of bank guarantee by private sectors on the long-term behavior}

To illustrate the effect of the Cost of bank guarantee by private sectors on long-term strategy selection based on the Cost of bank guarantee for private sectors, which is shown in Figure 6.

As expected, the increase in bank guarantee costs reduced the private sector's inclination to technology development and performing contract. 


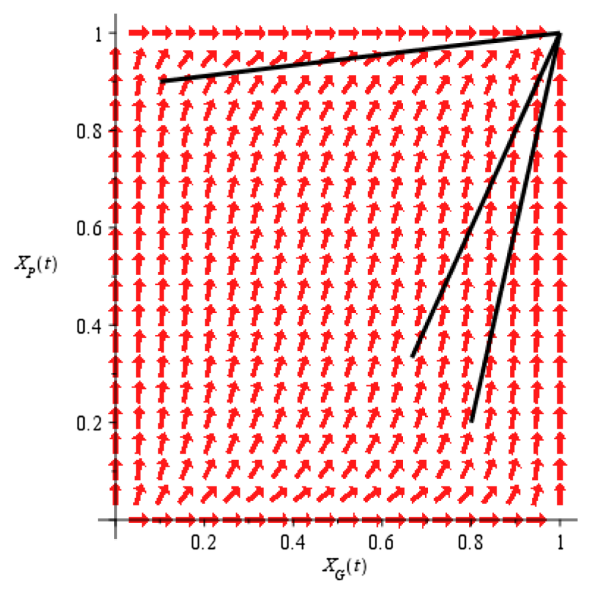

$50 \%$ decline

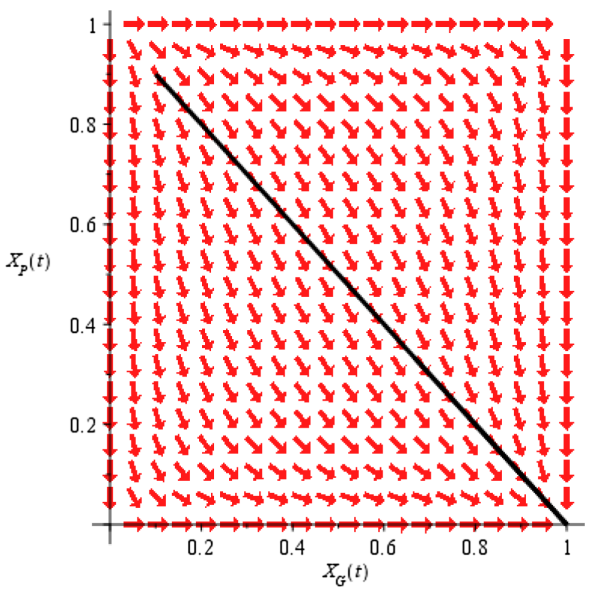

2-fold increasing

Figure 5. The effect of Cost of CHR, R\&D, and production (CP, R\&D, HR) on the long-term strategies.

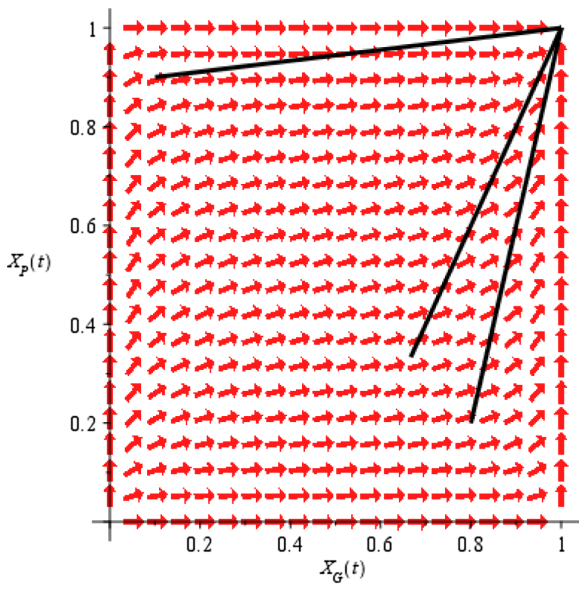

Increase \& decrease

Figure 6 . The effect of the Cost of bank guarantee by private sectors $\left(\mathrm{CP}_{B}\right)$ on the long-term strategies.

\subsection{The effect of Cost of currency fluctuations on the long-term behavior}

To illustrate the effect of the Cost of currency fluctuations on policy selection, based on the Cost of currency fluctuations, sensitivity analysis is performed, which are shown in Figure 7.

As it is seen, the Cost of currency fluctuations has a considerable effect on game results. By a $50 \%$ increase in the cost of currency fluctuations, private sectors don't tend to perform technology development. The convergence of the trajectories from $(1,1)$ to $(0,1)$ clearly shows this. By decreasing the cost of fluctuations from $3200 \mathrm{M} \$$ to $0 \$$, the long-term behavior of the government sector tends to incentive policies. Thus, increasing costs of currency fluctuations can prevent performing contract and technology development. 

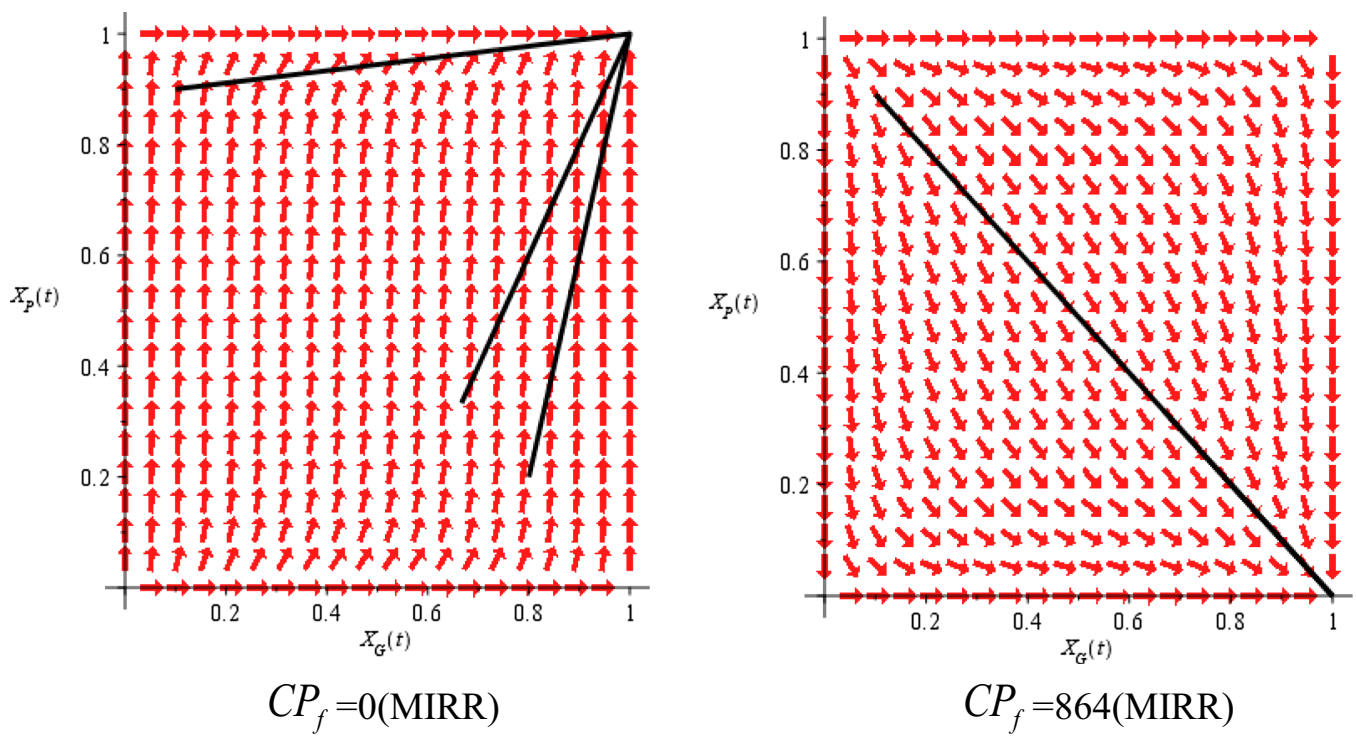

Figure 7 . The effect of the Cost of currency fluctuations $\left(\mathrm{CP}_{f}\right)$ on the long-term strategies.
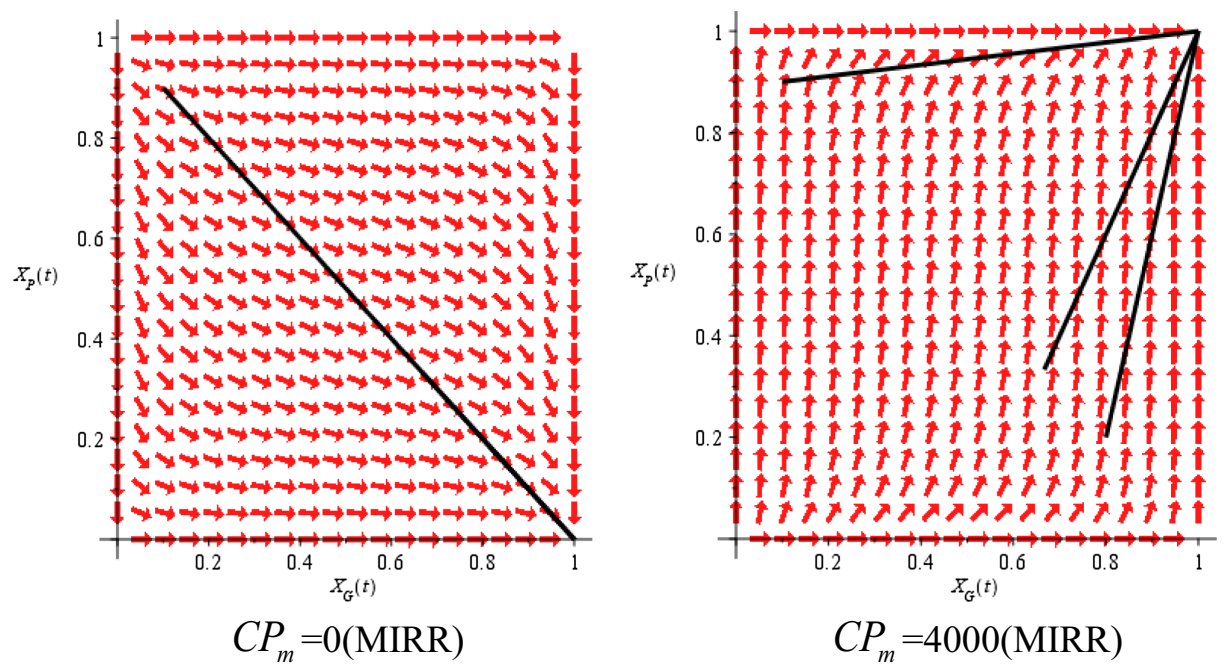

Figure 8. The effect of Cost of moral hazards $\left(\mathrm{CP}_{m}\right)$ on the long-term strategies.

\subsection{The effect of Cost of moral hazards on long-term behavior}

To illustrate the effect of the Cost of moral hazards on policy selection, based on the penalty for Cost of moral hazards, the sensitivity analysis is performed, which are shown in Figure 8.

As it is seen, the Cost of moral hazards has a considerable effect on game results. by a $100 \%$ increase in Cost of moral hazards, government sectors tend to incentive policies and decreasing the cost of fluctuations from $3200 \mathrm{MIRR}$ to 0 , it makes long-term behavior of private sector shifts not to perform technology development. This is completely illustrated by converging the trajectories from $(1,1)$ to $(0,1)$. 


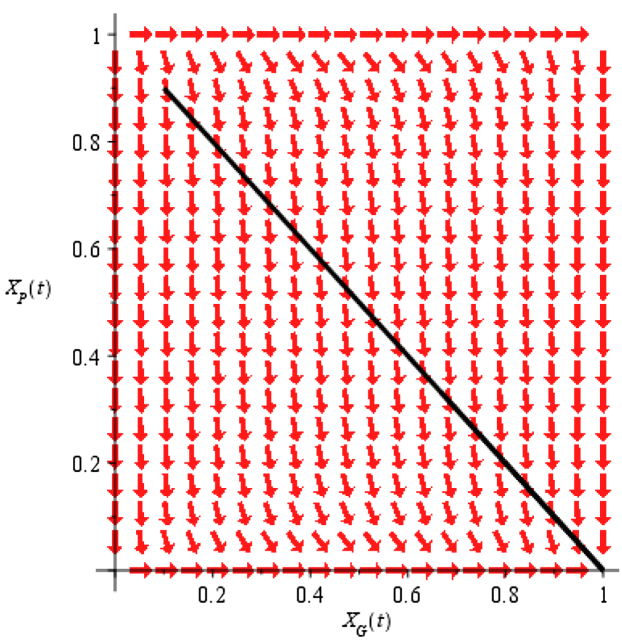

$\mathrm{X}=1$

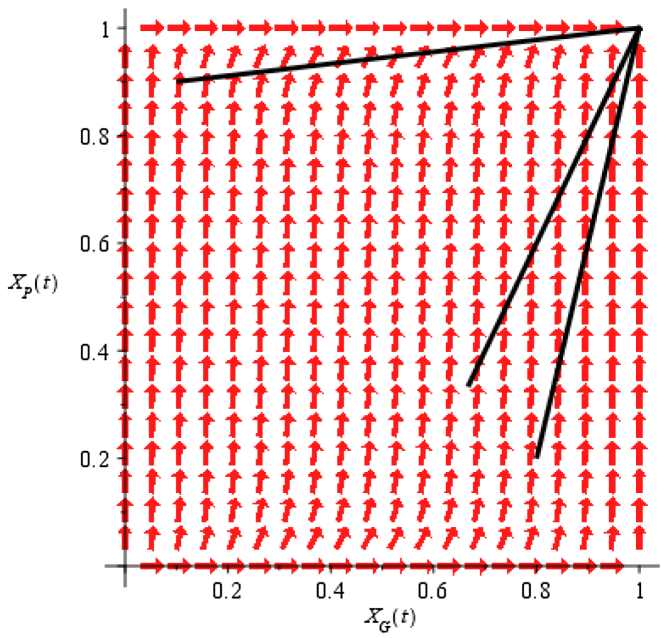

$\mathrm{X}=0$

Figure 9. The effect of the Proportion of private sectors breaking the ethics $(X)$ on the long-term strategies.

\subsection{The effect of the Proportion of private sectors breaking the ethics on long-term behavior}

To illustrate the effect of the Proportion of private sectors breaking the ethics on policy selection, based on penalty for the Proportion of private sectors breaking the ethics, the sensitivity analysis is performed, which are shown in Figure 9.

As it is seen, the Proportion of private sector breaking ethics has a considerable effect on game results. If all of the private sectors break the ethics, then government sectors tend to incentive policies and the private sector tends not to perform technology development. If all of the private sectors tend to ethics, it makes the long-term behavior of government sector shifts to regulation policies and performing contract truly. This is completely illustrated by converging the trajectories in Figure 9.

\section{CONCLUSiOn AND POLICY impliCATiOnS}

Based on analyzes of technology development model, the ten groups of the oil industry as a megaproject in a developing country, the following policy outcomes and suggestions are presented to improve the co-operation of policymakers to develop technology:

(1) Based on the results of data. The project often commodity groups as one of the largest technology development project in Iran, the main approach of the government, with minimal incentive mechanisms, should be legal monitoring. Costs and data may remain at the existing level and in the case of Increasing costs should increase the incentive mechanism and if the costs of companies rise from a certain level, then incentive mechanisms must be designed to mitigate the underlying problems of private companies. When this development creates risks, the development of technology limited to strict and direct regulations only reduces the welfare of private companies. The outcome of the execution of this contract is not the development of technology and is high losses for Iran.

(2) When a situation is set for technology development, the state should pay much attention to corporate feedback, must maintain a high level of transparency, and must reduce the conflict between firms and government by designing incentive mechanisms and regulations and an appropriate monitoring system. 
The result is appropriate Mutual respect between the parties, which will a win-win situation that will cause both the development of equipment technology and the company's activities to be properly offset.

(3) The most important and interesting item regarding the analysis is that the important factor in project implementation is the attention to private sector revenues and expenditures, and government revenues and expenditures have little effect on the results and behavior change, and this again demands the government's attention. Choosing the right policy options for corporate prosperity, transparency, trust, and finally contract appreciation and technology development.

(4) The government's lack of attention to the welfare of the private sector can lead to an increase in moral problems in the private sector. As a result, the government must take into account the minimum incentive mechanisms, including subsidies, etc., and ensure that the government's main policy is still legal oversight.

(5) It is very important to have better coordinate and collaborate with various government policymakers to provide better mechanisms and motivational cases. Many of the incentives offered by the companies are beyond the control of the Ministry of Oil. Institutions such as the Ministry of Industry, the Vice-President of Science and Technology, the Tax and Customs organization, their cooperation and coordination with the Ministry of Oil are very important and influential.

(6) Public sector flexibility is very important in cooperation with private companies. Given the economic turmoil, such as fluctuations in the price of foreign exchange, various laws, and internal and external conditions, the government should be flexible in implementing the contract and, to some extent, be flexible in its dealings and expectations with companies. And, by the environmental conditions, adjust its expectations and commitments.

(7) The choice of standard equipment production should be carefully evaluated by the government and its managers. If large-scale projects are executed by short-term managers, they do not have the incentive to consider private companies. In such cases, they focus on short-term benefits instead of focusing on long-term benefits to equipment. Given this mentality, we should avoid potential moral dilemmas when evaluating the implications for public management.

(8) When designing the technology development mechanisms of its ten commodity groups and policies, the government must consider all the factors and have a global understanding. Given the government policy, even if the government has long-term policies or large parts for private companies throughout. The initial performance is unknown, these companies, according to the performance and behavior of the government and its observers, gradually complete their work and update their beliefs.

\section{REFERENCES}

[1] S. Alizamir, F. de Vericourt and P. Sun, Efficient feed-in-tariff policies for renewable energy technologies. Oper. Res. 64 (2016) $52-66$.

[2] M. Almus and D. Czarnitzki, The effects of public R\&D subsidies on firms' innovation activities: the case of Eastern Germany. J. Bus. Econ. Stat. 21 (2003) 226-236.

[3] K.J. Arrow, Uncertainty and welfare economics of medical care. Am. Econ. Rev. 53 (1963) 941-973.

[4] A.L. Atasu, N. Van Wassenhove and M. Sarvary, Efficient take-back legislation. Prod. Oper. Manage. 18 (2009) $243-258$.

[5] P. Bardhan, The new institutional economics and development theory: a brief critical assessment. World Dev. 17 (1989) 1389-1395.

[6] R. Beason and D.E. Weinstein, Growth, economies of scale, and targeting in Japan (1955-1990). Rev. Econ. Stat. 78 (1996) 286-295.

[7] R. Belderbos, M. Carree and B. Lokshin, Cooperative R\&D and firm performance. Res. Policy 33 (2004) $1477-1492$.

[8] G. Berenguer, Q. Feng, J.G. Shanthikumar and L. Xu, The effects of subsidies on increasing consumption through for-profit and not-for-profit newsvendors. Prod. Oper. Manage. 26 (2017) 1191-1206.

[9] F. Bergstrom, Capital subsidies and the performance of firms. Small Bus. Econ. 14 (2000) 183-193.

[10] J. Chemama, M.C. Cohen, R. Loble and G. Perakis, Consumer subsidies with a strategic supplier: commitment vs. flexibility. Manage. Sci. 65 (2019) 459-954.

[11] Y. Chen, S. Ding, H. Zheng, Y. Zhang and S. Yang, Exploring diffusion strategies for mHealth promotion using the evolutionary game model. Appl. Math. Comput. 336 (2018) 148-161.

[12] M.C. Cohen, R. Lobel and G. Perakis, The impact of demand uncertainty on consumer subsidies for green technology adoption. Manage. Sci. 62 (2016) 1235-1258. 
[13] P. Criscuolo, N. Nicolaou and A. Salter, The elixir (or burden) of youth? Exploring differences in innovation between start-ups and established firms. Res. Policy 41 (2012) 319-333.

[14] D.F. Drake, P.R. Kleindorfer and L.N. Van Wassenhove, Technology choice and capacity portfolios under emissions regulation. Prod. Oper. Manage. 25 (2016) 1006-1025.

[15] M. Esmaeili, G. Allameh and T. Tajvidi, Using game theory for analyzing pricing models in the closed-loop supply chain from short-and long-term perspectives. International Journal of Prod. Res. 54 (2016) 2152-2169.

[16] C. Freeman and L. Soete, The Economics of Industrial Innovation. Psychology Press (1997).

[17] J.L. Furman and R. Hayes, Catching up or standing still?: National innovative productivity among "follower" countries, 1978-1999. Res. Policy 33 (2004) 1329-1354.

[18] G. George, A.S. Zahra and D.R. Wood, The effects of business-university alliances on innovative output and financial performance: a study of publicly traded biotechnology companies. J. Bus. Venturing 17 (2002) 577-609.

[19] M.C. Hu and J. Mathews, National innovative capacity in East Asia. Res. Policy 34 (2005) 1322-1349.

[20] M.C. Hu and J. Mathews, China's national innovative capacity. Res. Policy 37 (2008) 1465-1479.

[21] S. Hwan and J. Tianjun, Government subsidies for green technology development under uncertainty. Eur. J. Oper. Res. 286 (2020) 726-739.

[22] P. Ingram and P.W. Roberts, Friendships among competitors in the Sydney hotel industry. Am. J. Soc. 106 (2000) $387-423$.

[23] K.N. Kang and H. Park, Influence of government R\&D support and inter-firm collaborations on innovation in Korean biotechnology SMEs. Technovation 32 (2012) 68-78.

[24] D. Krass, T. Nedorezov and A. Ovchinnikov, Environmental taxes and the choice of green technology. Prod. Oper. Manage. 22 (2013) 1035-1055.

[25] M. Lee and K. Om, Different factors considered in project selection at public and private R\&D institutes. Technovation 16 (1996) 271-275.

[26] B.W. Lin, Y. Lee and S.C. Hung, R\&D Intensity and commercialization orientation effects on financial performance. J. Bus. Res. 59 (2006) 679-685.

[27] R. Lobel and G. Perakis, Consumer choice model for forecasting demand and designing incentives for solar technology. University of Pennsylvania, Working paper (2011).

[28] R.E. Lucas, On the mechanics of economic development. J. Monetary Econ. 22 (1997) 3-42.

[29] X. Luo, A. Rindfleisch and D.K. Tse, Working with rivals: The impact of competitor alliances on financial performance. J. Marketing Res. 44 (2007) 73-83.

[30] L. Ma and P. Zhang, Game analysis on the moral hazard of construction project managers in China. Int. J. Civ. Eng. 12 (2014) 429-438.

[31] X. Ma, W. Ho, P. Ji and S. Talluri, Coordinated pricing analysis with the carbon tax scheme in a supply chain. Decis. Sci. 49 (2018) 863-900.

[32] E. Mansfield, J. Rapoport, J. Schnee, S. Wagner and M. Hamburger, Research and Development in the Modern Corporation London, NY (1971).

[33] M.J. Nieto and L. Santamaria, The importance of diverse collaborative networks for the novelty of product innovation. Technovation 27 (2007) 367-377.

[34] N. Pangarkar and J. Wu, Alliance formation, partner diversity and performance of Singapore firms. Asia Pac. J. Manage. 30 (2013) 791-807.

[35] R. Radner, Monitoring cooperative agreement in a repeated principal-agent relationship. Econometrica (1981) $1127-1148$.

[36] G. Raz and A. Ovchinnikov, Coordinating pricing and supply of public interest goods using government rebates and subsidies. IEEE Trans. Eng. Manage. 62 (2015) 630-639.

[37] T. Rees, An Introduction to Evolutionary Game Theory. UBC Department of Computer Science, Vancouver, Canada (2005).

[38] I. Ritzenhofen, J.R. Birge and S. Spinler, The structural impact of renewable portfolio standards and feed-in-tariffs on electricity markets. Eur. J. Oper. Res. 225 (2016) 224-242.

[39] P. Romer, Endogenous Technological Change. National Bureau of Economic Research (1989).

[40] H. Rubinstein, Equilibrium in super games with the overtaking criterion. J. Econ. Theory 21 (1979) 1-9.

[41] J.A. Schumpeter, The Theory of Economic Development: An Inquiry into Profits, Capital, Credit, Interest, and the Business Cycle. Transaction Publishers 55 (1934).

[42] G. Shrimali and E. Baker, Optimal feed-in tariff schedules. IEEE Trans. Eng. Manage. 59 (2012) 310-322.

[43] R.M. Solow, A contribution to the theory of economic growth. Q. J. Econ. 70 (1956) 65-94.

[44] Ten commodity report, Research Institute of Sharif University (RISTIP) (2018).

[45] B.S. Tether, Who co-operates for innovation, and why: an empirical analysis. Res. Policy 31 (2002) $947-967$.

[46] D. Tzelepis and D. Skuras, The effects of regional capital subsidies on firm performance: an empirical study. J. Small Bus. Enterprise Dev. 11 (2004) 121-129.

[47] Y. Wang and Z. Zhou, A.Botterud. An evolutionary game approach to analyzing bidding strategies in electricity markets with elastic demand. Energy 36 (2011) 3459-3467.

[48] W. Wang, M.E. Ferguson, S. Hu and G.C. Souza, Dynamic capacity investment with two competing technologies. Manuf. Serv. Oper. Manage. 15 (2013) 616-629.

[49] J. Wind and V. Mahajan, Issues and opportunities in new product development. J. Marketing Res. 34 (1997) 1-12.

[50] J. Wu, The asymmetric roles of business ties and political ties in product innovation. J. Bus. Res. 64 (2011) $1151-1156$. 
[51] J. Wu and X.Y. Chen, Leaders' social ties, knowledge acquisition capability and firm competitive advantage. Asia Pac. J. Manage. 29 (2012) 331-350.

[52] D. Yanchao, H. Zhou, Y. Yuan and H. Xue, Exploring the moral hazard evolutionary mechanism for BIM implementation in an integrated project team. Sustainability 11 (2019) 5719.

[53] Y. Zhang and H. Li, Innovation search of new ventures in a technology cluster: the role of ties with service intermediaries. Strategic Manage. J. 31 (2010) 88-109.

[54] H. Zhang, L. Li, Z. Zhou and P. Zhou, Political connections, government subsidies and firm financial performance: evidence from renewable energy manufacturing in China. Renew. Energy 63 (2014) 330-336.

[55] H. Zhang, Z. Xu, D. Zhou and J. Cao, Waste cooking oil-to-energy under in-complete information: identifying policy options through an evolutionary game. Appl. Energy 185 (2017) 547-555.

[56] Y. Zhang, Y. Gu, M. Pan, N.H. Tran, Z. Dawy and Z. Han, Multi-Dimensional Incentive Mechanism in Mobile Crowdsourcing with Moral Hazard. IEEE Trans. Mob. Comput. 17 (2018) 604-616.

[57] W. Zhou and W. Huang, Contract designs for energy-saving product development in a monopoly. Eur. J. Oper. Res. 250 (2016) 902-913.

[58] Q.H. Zhu and Y.J. Dou, The evolutionary game model between governments and core enterprises in greening supply chains. Syst. Eng. Theory Prac. 27 (2007) 85-89. 